DANDELION

postgraduate arts journal \& research network

VOLUME 3 NUMBER I WINTER 2012: BREVITY
John A. Riley holds a PhD from Birkbeck College. Supervised by Professor Ian Christie, the thesis, entitled 'Shifting Mirrors: An Intertextual Approach to The Films of Andrei Tarkovsky' conceptualises the many resonances between Tarkovsky's films and the work of others as reflections, double exposures and hauntings. He writes about film for a wide variety of publications.

Email: jriley1981@gmail.com

Article

\title{
Tarkovsky and Brevity
}

\author{
John A. Riley
}

Brevity is not a word that springs to mind when one thinks of Andrei Tarkovsky. His film Stalker took two and a half hours to convey three men and a dog across a field. Tarkovsky's films, and his powerful creative personality, which often dominates the discourse around his work, have become part of the canon of world cinema. His films have become bywords for the lengthy, difficult, and wholly serious. But despite this reputation for sprawl, there was an undercurrent of concision in his thought and work. In this article, I will turn to a rarely discussed strand in Tarkovsky's art: his Polaroid photographs. ${ }^{1}$ I will contrast Tarkovsky's approach to Polaroid photography with the long form narrative experiments he undertook in film, in order to argue that, perhaps somewhat paradoxically, Tarkovsky appreciated brevity, and that an understanding of Tarkovsky's art that focuses on his mobilization of extended duration tells only a partial story. I will construct this argument against the stereotypical understanding of Tarkovsky as propagated by his own (in fact coauthored) book Sculpting in Time (1986). ${ }^{2}$

Sculpting in Time outlines traditional aesthetic beliefs (art as expression of beauty, beauty as expression of truth) alongside personal reflections and reminiscences. The book argues that cinema's unique property is the ability to capture time. This, he claims, is why he uses the long take: to capture large, unbroken sections of time. Sculpting in Time is often seen as a work of film theory. The book does have many factors in common with some of the canonical works of classical film theory: chiefly a desire to interrogate the essence of cinema, which Tarkovsky designates as the ability to record time. I 
would argue that we should see Sculpting in Time as a more personal, perhaps even in some ways ephemeral work, much like the diaries, where spur of the moment thoughts are recorded for posterity. Many writers on Tarkovsky who have used Sculpting in Time have treated it as existing in some kind of vacuum - the film theory can be placed over the films unproblematically, rather than seeing the book as the thoughts of Tarkovsky at a particular time in his life, interspersed with those of his uncredited co-author Olga Surkova, sometimes twenty years after the films being discussed were made.

In Sculpting in Time Tarkovsky claims his use of the long take was an attempt at 'faithfully recording on film the time which flows on beyond the edges of the frame.3 But what if we do not take the claims of Sculpting in Time at face value? What if, in his long takes, Tarkovsky was really searching for something that has been far more readily identified in photography? The photographic theory of Roland Barthes gives us the term punctum to describe the moment of rupture when we are shaken out of the official meaning of the photographic image as an objective document, and are personally affected by some small detail contained within it. I contend that it was these small, charged details that Tarkovsky was looking for in both his films and his photography.

Beginning with the biographical and emotional contexts of Tarkovsky's use of the snap shot, I will then describe Barthes' mobilization of the notion of the punctum, considering the brief flash of recognition that constitutes the punctum as part of an aesthetics of brevity. I will discuss how these uncanny images manifest themselves in Tarkovsky's films, through his celebrated use of the long take. After discussing Tarkovsky's long take as exemplified in the film Mirror (1975), I will draw parallels between Tarkovsky's films and his Polaroid portraits, finding the punctum present in their intersection. Following on from this, I discuss the Polaroids which I class as 'still life' and show how they reflect Tarkovsky's interest in the brevity and simplicity of Japanese aesthetics, through Barthes' suggestive comments linking Haiku and photography. Finding, in all of these photographs, that the punctum is mobilized through various kinds of juxtapositions, I conclude by discussing the way that Tarkovsky's lifelong fascination with 'double exposure' has emerged throughout his films and photography, which confirms his sensibility for the aesthetics of brevity.

\section{Tarkovsky's Snapshots}

Eight minute takes and action that slowly unfolds in real time would appear to be directly opposed to the idea of brevity, though Tarkovsky saw a closer relationship between the two. In his introduction to a collection of his Polaroids, Instant Light (2002), Tarkovsky's friend and collaborator Tonino Guerra relates an anecdote about Tarkovsky giving a Polaroid photograph to some Central Asian villagers, while location scouting in the region. Looking at the photograph, one of the villagers asked Tarkovsky 'why stop time?' Guerra goes on to comment: 'Tarkovsky often reflected on the way that time flies and this is precisely what he wanted; to stop it, even with these quick Polaroid shots. ${ }^{4}$ 
Tarkovsky had been fascinated with photography since childhood, when an accidental double exposure (usually achieved by taking a photograph and then not winding the film along) allowed two separate family members to be in the same space and time, one a ghostly overlay of the other. ${ }^{5}$ Natasha Synessios reports that this image, along with several other cherished photographs taken in the 1930s and 1940s, provided the inspiration for the autobiographical film Mirror. ${ }^{6}$ Celluloid was in high demand in the Soviet Union, and continued to be so throughout the stagnant 1970s. So Tarkovsky was indeed privileged when fellow film director Michelangelo Antonioni gave him a camera. ${ }^{7}$ Tarkovsky originally used the camera for the straightforward use of taking snaps at Guerra's wedding, at which Tarkovsky and Antonioni were witnesses. But his new acquisition came at a time when Tarkovsky was beginning to gravitate more and more towards the West. His work with photography thus coincides with a transition in his life, from his career in the culturally and economically stagnant USSR of the late seventies and early eighties, to his defection to Italy and his new life as an émigré artist in the West, preoccupied with his own nostalgia. ${ }^{8}$

In On Photography Susan Sontag suggests that, for those from workethic cultures, photographing tourist attractions removes feelings of anxiety, guilt, and uncertainty when not working. She calls it a 'friendly imitation of work'. ${ }^{9}$ For Tarkovsky, who waited long periods of time between film projects, photography would have seemed this very substitute, allowing the capture and presentation of a piece of reality. In his published diaries, Tarkovsky vents his frustrations at the slow pace of his working life on several occasions:

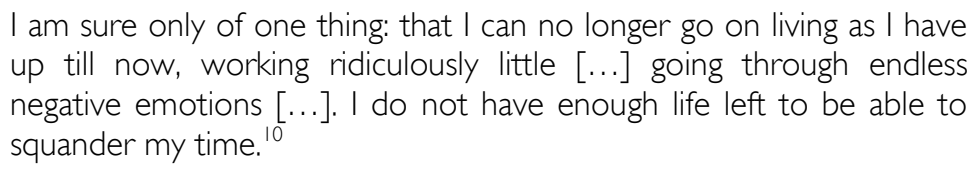

Sontag goes on to claim: 'When we are afraid, we shoot. But when we are nostalgic, we take pictures. ${ }^{, 11}$ Tarkovsky became afflicted with nostalgia to the point where he made a film about it, insisting the title be spelled as Nostalghia; a transliteration of what he felt was a word that the Russians had claimed as their own, for a particularly Russian condition. His preferred spelling demonstrated a scrupulous distinction between the impossibility of returning and mere fond reminiscences about the past. ${ }^{12}$

Sontag notes another of photography's seductive powers: 'Each still photograph is a privileged moment, turned into a slim object that one can keep and look at again. ${ }^{, 13}$ The impression Tarkovsky gives of himself in his diaries is of a materialistic, acquisitive man, despite public statements to the contrary. It must have excited him to have been given such a high-tech consumer item, when the $35 \mathrm{~mm}$ Kodak film stock he needed for his films was state property. Tarkovsky's feature films were the property of Mosfilm, while the Polaroids could express some of the same impressions and sentiments and yet be kept, or be given as gifts. The Polaroid medium could provide instant aesthetic satisfaction to a frustrated artist. Such, Tarkovsky discovered, are some of the virtues of brevity. 
Tarkovsky's Polaroids are collected in two volumes, Instant Light and Bright, Bright Day (published in a limited edition of 3000 in London in 2007), each with a slightly differing collection of photographs. They show a remarkable imagistic coherence with his films: country dachas swathed in mist; dense, green woodlands and domestic interiors that betray few traces of the modern. Many of the snapshots seem to reflect Tarkovsky's lush, dream-like world. They are devoid of what he saw as the detritus of popular culture and the garish intrusions of consumerism. A bluish or greenish tint, antique decor, a misty rural landscape: they could be stills from his films if they did not have the Polaroid's characteristic smudgy blur rather than the sharp focus of his cinematic images. Intermingled with these 'art' photographs are candid and posed portraits of his wife and son, Guerra, and other figures from his life. One reviewer of the 2007 White Space gallery exhibition commented that 'the portraits in the series are disarmingly personal, as though taken straight from the family photograph album, ${ }^{14}$

\section{The Punctum}

Barthes coined the term punctum in his final book Camera Lucida, simultaneously an attempt to divine the essence of the emotional impact of photography, a discussion of certain critically favoured photographs and their photographers, and a reflection on mortality through a photograph of Barthes' recently deceased mother. It is a slim, concise volume, and many of its thematic concerns closely mirror those of Tarkovsky's films, from the ghostly return of Solaris (1972) to the nostalgic remembrances of a mother figure found in Mirror. Barthes' willingness to go beyond the accepted parameters of the theorist and critic may be accounted for in this instance by what Laura Mulvey calls an 'almost bewildered fascination with the photograph as a phenomenon that goes beyond the intellectual and the aesthetic.' ${ }^{15}$ In the same way, Tarkovsky's reverent belief in the power of moving images contains an appeal to the sublime.

The common being between the photograph and its subject is understood by Barthes as forming photography's essence. Barthes' work on photography stems from an understanding that photography is a fraction of a second, embalmed, an imprint of a subject. He calls the more general way we look at photographs, in a culture awash with images, the studium. He opposes the studium to the punctum, which is the small, uncanny detail in certain photographs that pricks us, causes a personal response perhaps disproportionate to the information that the photograph contains. To give an example, photographs of disasters such as warfare and famine are printed daily in newspapers, to the point that they have become commonly accepted. But someone looking at a photograph of such carnage, focusing on some small detail such as the vulnerable sock-clad feet of a corpse, and being moved by this photograph, would be experiencing the punctum. In the photographs Barthes uses as examples he picks up on details such as a plaster on the thumb of a mentally disabled child, or the curious shoes of a woman in a family portrait. ${ }^{16}$ 
What allows us this experience, is the uncanny tense of the photograph, the fact that it is an embalmed fragment of time, a frozen and framed section of space. As Mulvey puts it:

\begin{abstract}
The photograph pushes language and its ability to articulate time to the limits of its possibility, leaving the spectator with a slightly giddy feeling, reminiscent of a trompe l'oeil. But since this is an oscillation of time rather than of space, it is even more abstract and difficult to articulate, and gives rise to that sense of uncertainty associated with the uncanny. ${ }^{17}$
\end{abstract}

But Barthes also understands the indexicality of the photograph as giving it a metonymic power, a 'power of expansion', a substitution of the part for a nebulous whole. ${ }^{18}$ This is how certain photographs become 'iconic', how they can come to stand as substitutes for an entire military conflict or political ideal. But Barthes makes clear as his book continues that the punctum is connected to mortality: it is a sudden, painful epiphany of our own fragility. Barthes comes to this realization through a reflection on a photograph of Lewis Payne, waiting in his cell to be executed, and finally by reflecting on a photograph of his recently deceased mother, taken when she was a child.

Films such as Tarkovsky's - slow paced, with scenes shot in long takes - facilitate an atmosphere where the punctum may be apprehended. Details of performance, scenery, etc., may suddenly jump out of the film and attain significance. Furthermore, as Mulvey argues, home video and DVD technology allow a closer relationship than viewings at the cinema: films can now be paused, rewound endlessly, and played in slow motion allowing us access to a film's punctum. This desire to be a 'possessive spectator' was, in an era prior to home entertainment formats such as VHS and DVD, stoked by photographs of movie stars.

The following commentary on Mirror's penultimate scene is borne of just such an in-depth scrutiny: watching and re-watching in slow motion and freeze frame, searching for a way to describe Terekhova's enigmatic performance, and the mystery that her gaze seems to hold. These remarks constitute my own subjective interpretation of a scene comprised of tiny gestures; someone else could draw entirely different conclusions based on Terekhova's facial expressions and head movements. The scene is a telling example of Tarkovsky's use of the long take and its capability for unlocking the punctum.

\title{
Brevity Within The Long Take
}

For filmmakers of a Bazinian/neorealist persuasion, the long take is the ultimate cinematic technique because it preserves large, unbroken chunks of profilmic reality. ${ }^{19}$ As Tarkovsky's career developed, he accorded the long take increasing prominence. Compared to the average feature film, Stalker (1979), Nostalghia (1983), and The Sacrifice (1986) contain very few shots, culminating in lengthy set-pieces like the climactic shot of Gorchakov carrying a candle in Nostalghia, and the opening and penultimate shots of The Sacrifice. 
In the mostly autobiographical Mirror, Tarkovsky cast Margarita Terekhova in two roles, standing in for both his own first wife and his mother. In the famous scene in which the mother waits, sitting on a fence, Tarkovsky gave Terekhova as little information as possible, so that her response would be ambiguous. The character doesn't know her future, so why should the actress? ${ }^{20}$ We see this same enigmatic quality at the close of the film, in the scene where Terekhova, again in the 'mother' role, has just discovered she is pregnant. Her husband asks if she would rather give birth to a boy or a girl.

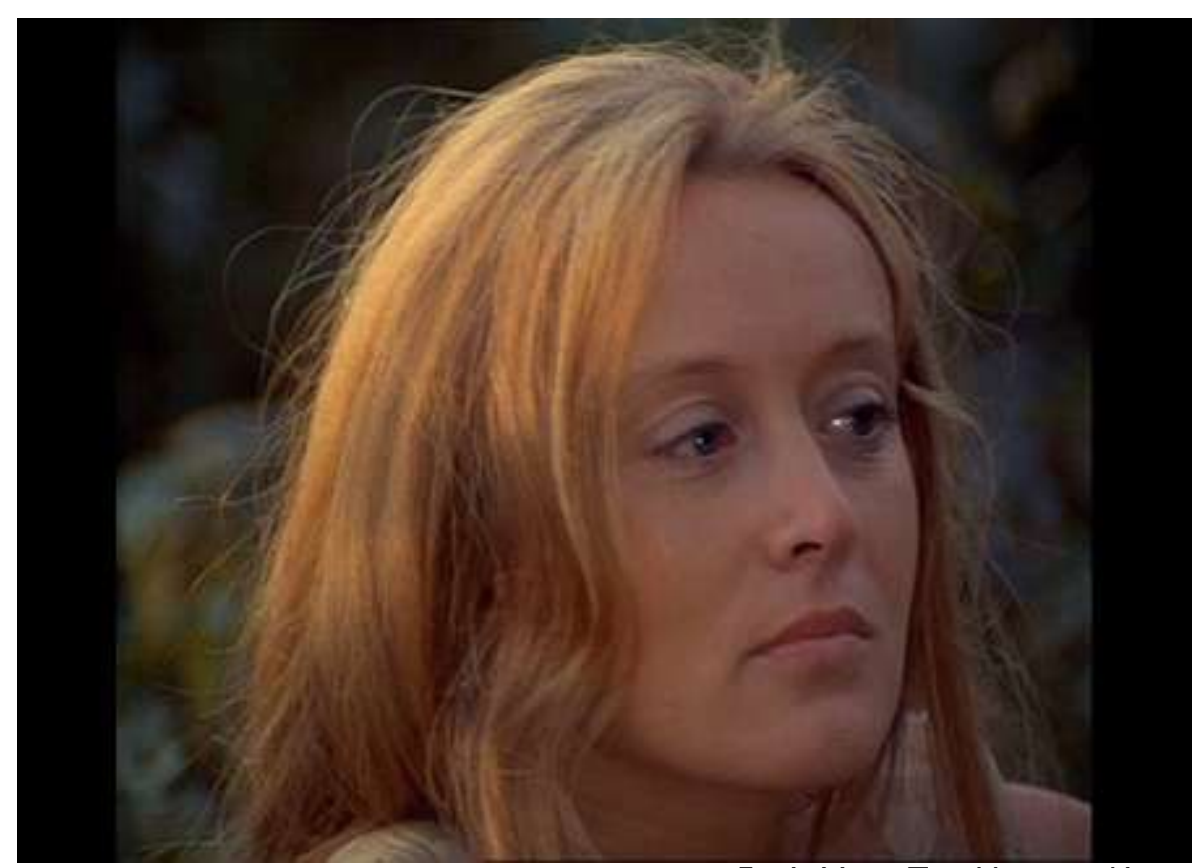

Fig I. Maria Terekhova in Mirror.

Just before her husband has spoken, Terekhova gets up from her position of lying on top of him, gazing into his eyes. As the camera rises to meet her, she sighs, looks worried, and brushes back her hair. Her lips move to a very slight smile before her husband asks the question. As he is finishing speaking she looks back at him, smiling almost mischievously. Then she turns away from him again, sighs very audibly, and her expression suddenly looks incredibly weary and nervous. Then she bites her lip as if to stop herself crying, and cranes her head back towards her husband. This time her mischievous smile is directed at the camera rather than at him. Suddenly she inhales sharply and audibly and turns her head away from us to look through the trees back to her house, and we see her 'bun' hairstyle, prominent in the scene near the start of the film, depicting Maria waiting on the fence. The film then cuts to a tracking shot through the trees of Ignatievo forest, and we catch a glimpse of Tarkovsky's actual mother, bun firmly in place.

Tarkovsky shows a variety of facial expressions provoked by only one verbal stimulus. Her expressions could be signs of any number of emotions: fear, happiness, sudden distraction, etc. By lingering on this moment, the 
filmmaker also allows a crack to form in the fiction: if we look long and hard enough we also see an actress unsure of what to do, looking nervously at the camera.

Despite their slow pace, the final two films Nostalghia and The Sacrifice compress time at key moments, so we no longer have a 'realistic' idea of a time scale for the events we see unfolding. In Nostalghia Gorchakov lies down in his hotel room, and over a few minutes, we see the light change as night rapidly becomes morning. In practice this is a long take, but it is in fact a sequence which compresses several hours into a few minutes, while the light source was gradually increased outside the window to give the effect of a sunrise. At the conclusion of The Sacrifice, in the film's penultimate shot, we find the same compression of time, when police and an ambulance seem to arrive at a burning house almost immediately, with no one around to call for either. A filmmaker such as Bela Tarr would insist that we see these events in real time, while Tarkovsky opts for a concise compression of time that points to his interest in brevity.

\section{Brevity and Portrait Photography}

In Camera Lucida, Barthes restricts his discussion of the punctum to photographs that contain human figures. Tarkovsky's Polaroid portraits are, for the most part, of people close to him: family and close friends about whom he undoubtedly felt a complex range of emotions. These personal mementoes, metonyms for his relationships with these figures, are rendered more complex by the self-reflexive commentary which Tarkovsky includes.

Traces of self-reflexivity are also brief instances of Tarkovsky's celebration of the Polaroid medium's power to capture brevity. In Tarkovsky's photographic oeuvre, self-reflexivity takes the form of the medium's own intrusion into its output: many of the images have Polaroids, or Polaroid cartridges within them. Perhaps the best example of this is a portrait of Tarkovsky, presumably taken by his wife Larissa. The photograph shows Tarkovsky in bed, eating a meal from a tray, with his glasses and several empty Polaroid cartridges by his side. Tarkovsky looks surprised, mock-annoyed, and there is the intrusion of a small black square at the top of the frame, just to the right of his head. The brevity aesthetic encapsulated by the punctum here is an intertextual one, recalling the conclusion of Hollis Frampton's aptly titled filmic farewell to photography (nostalgia) (1971), a film with an almost identical title (both titles are adornments or variations upon the word nostalgia, and both reflect upon the condition of nostalgia's relation to emotional pain through a mobilization of imagery of fire). At one point in Frampton's film, the narrator speaks of the horror of finding an uncanny black speck on one of the photographs he has developed, and the powerful feeling of unease that this causes. ${ }^{21}$

The artlessness of this portrait of the director is the perfect counterweight to Tarkovsky's own portrait of Larissa who is obviously posing, a faded beauty theatrically clutching a vase of flowers. ${ }^{22}$ A further image from Bright, Bright Day depicts her in profile, as if looking away due to intensity of emotion. She clutches a Polaroid in her hands, picture side turned inwards as if 
what it depicts is too moving and must remain hidden. Another profile of Larissa shows her leaning against an outside wall. Golden light floods the photograph from the left-hand side of the frame, casting a huge shadow behind Larissa. She has the same sad, downcast eyes as she gazes at a single rose. ${ }^{23} \mathrm{Her}$ eyes, and her position at a dining table, recall and complement Stalker's concluding image of a girl at a table, reciting Fyodor Tyutchev's poem in tribute to the aesthetic virtue of downcast eyes. This portrait suggests that Tarkovsky agreed with Tyutchev on this point, but once again the photograph bears a punctum that is a metonym for something else: details from Tarkovsky's films are found even within a small detail from a personal photograph. The downcast eyes are another intertextual signifier of brevity: the image stands for moments of intense intimacy and of personal emotion, expressed concisely in a photographic image. Not all of Tarkovsky's Polaroids are personal portraits, however. Many are depopulated and qualify as still life photography. In the next section, I will consider the way in which other forms of brevity can be apprehended in these Polaroids.

\section{The Haiku and Still Life Photography}

In Sculpting in Time, Tarkovsky expressed his interest in the Haiku, the traditional Japanese poem of three lines that perhaps represents the pinnacle of an aesthetics of brevity in literature. What Tarkovsky claimed attracted him to the Haiku was the reportage of the form, its 'observation of life - pure, subtle, one with its subject. ${ }^{24}$ He goes on to say that 'prose and poetry use words by definition, while a film is born of direct observation of life; that, in my view, is the key to poetry in cinema'. ${ }^{25}$ Implicit in Tarkovsky's thought is a connection between poetic observation and photographic reproduction of reality, as if for him they were not so opposed as one might think. For example here is one of Basho's Haiku, cited in Sculpting in Time:

Coldly shining moon

Near the ancient monastery

A wolf is howling. ${ }^{26}$

Basho focuses on the objective, describable characteristics (the moon, the location, audible sounds) rather than his own feelings. But the purpose of the poem is precisely to get across an emotional mood through an objective, depersonalized technique and a focus on objects and locations rather than feelings and people. Also, it is significant that the poem moves from one image (and in this case, sound) to the next as we move to the next line. As the scholar of Japanese poetry Makoto Ueda notes: 'Two disparate objects are abruptly juxtaposed, with little or no explanation. There is little logical connection between the two objects presented in each Haiku. Yet the juxtaposition of the two objects produces a strangely harmonious mood. ${ }^{27}$ Ueda is here suggesting that Haiku are constructed from juxtapositions of objects or locations.

For Tarkovsky, a photographic or cinematic image is like a Haiku in so far as it is capable of concisely expressing a poetic image, or of reporting a brief slice of information that can come to stand in for something much larger. We 
shall see how Tarkovsky was also interested in creating juxtapositions and combinations of objects and locations.

Barthes too connects the Haiku to photography, highlighting the paradoxical qualities of that style of poetry by comparing it to trying to take a photograph without film:

Here meaning is only a flash, a slash of light: When the light of sense goes out, but with a flash that has revealed the invisible world, Shakespeare wrote; but the Haiku's flash illumines, reveals nothing; it is the flash of a photograph one takes very carefully (in the Japanese manner) but having neglected to load the camera with film. ${ }^{28}$

For Barthes, the aim of Haiku poetry is to limit meaning, to be brief, to express something that just is. This limiting of meaning somewhat paradoxically allows the Haiku to take on greater significance than if symbolism were used. Barthes saw photography as having these same qualities. In Camera Lucida, he observes:
A trick of vocabulary: we say 'to develop a photograph'; but what the chemical action develops is undevelopable, an essence (of a wound), what cannot be transformed but only repeated under the instances of insistence (of the insistent gaze). This brings the Photograph (certain photographs) close to the Haiku. For the notation of a Haiku, too, is undevelopable: everything is given, without provoking the desire for or even the possibility of a rhetorical expansion [... n neither the Haiku nor the Photograph makes us 'dream.'. 29

Many Haiku aim to express mono no aware, a concept from traditional Japanese aesthetics, best understood as a bittersweet acceptance of transience and fragility. The fleeting nature of events is celebrated and mourned at the same time. This bittersweet feeling, a wounded reaction to time's passing, recalls the punctum. The word aware has connotations of 'touchingness', just as Barthes deliberately chose the term punctum because of its associations with being touched, pricked, or wounded. In mono no aware, feelings are often expressed through objects, by moving away from people and their overt expressions of emotion. Japanese film director Yasujiro Ozu is a notable example of a practitioner of this thematic principle. Through emotionally turbulent times his characters say little and remain impassive, while Ozu picks up on a small detail such as an empty chair, or a character peeling an apple. ${ }^{30}$ In his Late Spring (1949), for example, a father convinces his daughter that he wants to remarry, so that she will stop taking care of him and take a husband herself. His selfless act leaves him alone. At the film's climax, father and daughter depart from a room, and a shot, leaving the viewer looking at an ordinary chair in front of a mirror. Critic and filmmaker Yoshida comments: 'When the two gazes interact, the meaning of this chair becomes limitlessly amplified. The chair indicates the daughter's departure. Simultaneously, it declares the loneliness of the father who is left behind. ${ }^{31}$ Tarkovsky's 'still life' Polaroids express just this kind of aesthetic. By limiting symbolic or rhetorical 
meaning they allow another, more lyrical and concise experience. Consequently they are also examples of a kind of Haiku aesthetic.

Many of the published photographs collected in the two volumes relate to Nostalghia, as they were taken while Guerra and Tarkovsky travelled Italy, looking for suitable filming locations and for places that would inspire them to write. The statue of an angelic figure with a towel draped over it recalls the unlikely appearance of a winged angel during the film. ${ }^{32}$ In its juxtaposition of the sacred with the quotidian the photograph evokes an imperfect beauty: the classical proportions of a statue are intruded upon by the everyday, and the relative permanence of the stone sculpture compared to the transient, brief human element. The 'rhetoric' of this photograph chimes with Tarkovsky's spiritual questing, his dissatisfaction with the trappings of the everyday. However, the brevity of the photographic medium means that meaning may be apprehended instantaneously, unlike the corresponding scene in Nostalghia, which unfolds over a matter of minutes, and is not easy to apprehend on DVD or television, where the angels' wings appear indistinct.

The statue photograph is not the only one of Tarkovsky's Polaroids featuring a human effigy whose face we cannot see: another depicts a child's doll, beheaded. ${ }^{33}$ It is hard to tell if this photograph is entirely posed for the camera. Tarkovsky had a talent for assembling diverse pieces of junk into an aesthetically beautiful assemblage, as Evgeny Tsymbal, his assistant on the set of Stalker, revealed in lectures while in London. ${ }^{34}$ It may be that the objects were found at the location (by the pool at Bagno Vignoni, while location scouting for Nostalghia) and arranged for the camera. The image tellingly recalls surrealism and dada, the unworkable contraptions of surrealists such as Francis Picabia, notably his painting Parade Amoureuse (1919), although with the characteristic weather-beaten (in this case almost calcified) look that Tarkovsky loved in Japanese art and culture.

A similar photograph of a doll appears, pinned to the wall of Domenico's hermit-hole, in Nostalghia. In the film, when Gorchakov moves to examine the photograph, we see that its corners are charred, and as the camera moves closer we see the subject, a child's doll, the grimy and cracked effigy of a baby. This image recalls Stalker's supposed prediction, or if you prefer, eerie foreshadowing, of the Chernobyl nuclear disaster of 1986. Since then 'extreme tourists', in some ways resembling the stalkers of Roadside Picnic (1972), have crossed the barrier into the cordoned-off zone around the power station and returned with photographic evidence of the deserted towns and villages, including several memorable images of abandoned dolls and toys. ${ }^{35}$ On its original release in 1983, the cinematic image from Nostalghia would have held none of its current power, through its association with the Chernobyl disaster. However, viewed today it gives a peculiar, intertextual punctum to its photographic counterpart, this image of broken objects arranged by a wall. Conversely, we are again instantly able to apprehend something of Tarkovsky's cinematic universe within a single, small frame that holds a captured fraction of a second. It is as if this photograph stands as a concise metonym for the enveloping, mossy world of Nostalghia.

Nostalghia announces its culture-clash motif from its very beginning, when a plaintive Russian folk sound is drowned out by Giuseppe Verdi's 
Requiem (1874) on the soundtrack. The same theme is articulated at the end of the film, when we see a Russian dacha enclosed within the ruins of an Italian Cathedral. While scouting for locations in Civitavecchia, Tarkovsky and his party found a cemetery in front of a petroleum deposit. His photograph from that day presents an abrupt contrast between the white marble headstones and the four ominous, black petrol drums looming above. ${ }^{36}$ The feeling of mono no aware is here evoked through the setting of human mortality against the vast indifference of the industrial tanks. For the Tarkovsky enthusiast, again an uncanny feeling is apprehended: many theories abound that Tarkovsky's fatal cancer was caused by filming parts of Stalker in a disused chemical plant. A shot near the end of the film makes a similar juxtaposition to that of this photograph: three fragile-looking human figures in the foreground with a huge factory belching out smoke behind them. While this shot tracks the figures for minutes until they reach a vantage point where the huge power station can be seen, the Civitavecchia photograph makes an instantaneous, concise juxtaposition. The photograph expresses the feeling of mono no aware not by setting the grim physical reality of death against machinic indifference, but by focusing on the unadorned beauty of the rural graves. This photograph resembles the aim of many Haiku, to express mono no aware, in its focus on objects and location over people, and in its technique of juxtaposition. It highlights the fact that Tarkovsky's rhetorical strategy was frequently one of juxtaposition, but without the density of duration found in the films. The brevity of the photographic form makes this far more apparent.

\section{The Double Exposure}

The double exposure embodies another example of Tarkovsky's fascination with the aesthetics of brevity. In many ways, he was less concerned with his audience experiencing an extended duration (the 'actual waiting time' that Bazin celebrated) than he was in suddenly bringing two unexpected times and places together in a single moment. Although impossible with a Polaroid camera, one of the things that attracted Tarkovsky to photography was the double exposure.

Fascinated by this photographic property since childhood, Tarkovsky would later use an anecdote about a photograph with eerie properties that can be explained by accidental double exposure into the dialogue of The Sacrifice. The anecdote is told by Otto, the postman, who seems at first quite an everyday character, but is soon revealed to have seer-like qualities. The tale is as follows. A woman goes to pose for a photograph with her son. War breaks out, and in the chaos her son is killed and she never collects the photograph. Years later, when she poses for another photographic portrait, the subsequent photograph is a double exposure with the ghostly image of her long-dead son pictured next to the now-elderly woman. I believe that this kind of ghostly juxtaposition is a recurring theme in Tarkovsky's work. The clash of Verdi and Russian folk lament on the soundtrack of Nostalghia is a further example of Tarkovsky's interest in double exposure, which allowed him to concisely superimpose themes and moods. 
In her book The Future of Nostalgia, Svetlana Boym makes an enigmatic remark about nostalgia's relation to the cinema:

A cinematic image of nostalgia is a double exposure, or a superimposition of two images - of home and abroad, past and present, dream and everyday life. The moment we try to force it into a single image, it breaks the frame or burns the surface. ${ }^{37}$

It was Tarkovsky's aim though, to force these separate components into a single image, hence the Civitavecchia photograph, or the image of the Russian dacha held impossibly within the ruins of an Italian cathedral at the end of Nostalghia.

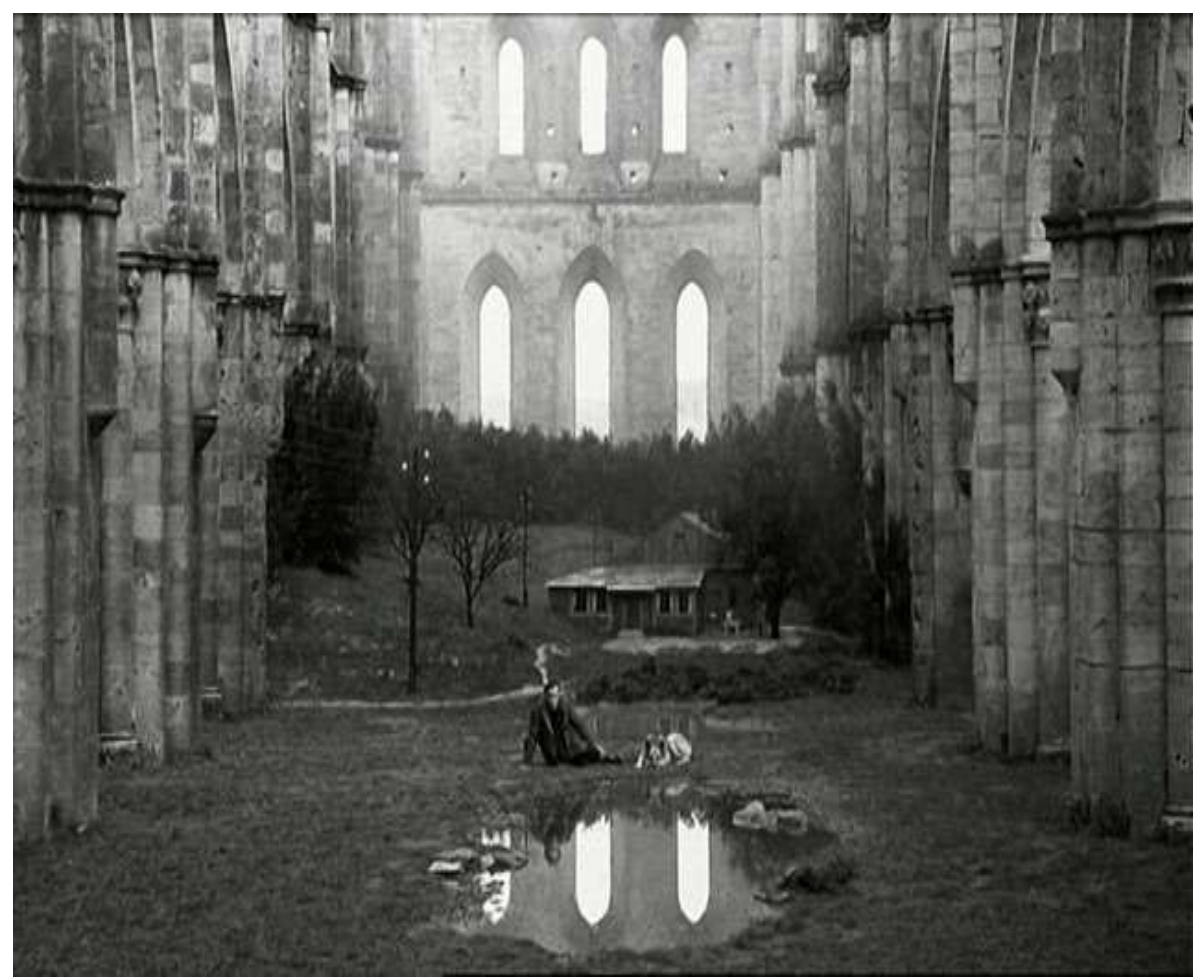

Fig 2. Still from Nostalghia: The Russian dacha within the Italian cathedral

In The Sacrifice Alexander gives up his home and family in order to avert a nuclear holocaust, but still (unnecessarily according to the bargain Alexander makes with God) sleeps with a female with mysterious powers. Tarkovsky scholars Vida Johnson and Graham Petrie note that the film's script is an amalgamation of two scripts. It incorporates elements of an earlier script called The Witch that told the story of a man cured of illness through sexual congress with a magical woman. They conclude that 'the merging of the original and new storylines produces disharmony and confusion on the level of plot. An unexplained double sacrifice is created [...]. This results in a frustrating absence of thematic and philosophical coherence that ultimately damages the film?. 
This is a very literal reading of the film, and the incredulity towards the unexplained aspects of Tarkovsky's cinema demonstrates an unwillingness to approach the ambiguity and density of the works. Johnson and Petrie attempt to impose a single, straight line onto Tarkovsky's narrative, against his forking conception of time. In fact, the merging of the two scripts means that the entire film is structured along the lines of a double exposure. Tarkovsky moves from a literal understanding of the double exposure to a more abstract, conceptual use that allows for traces of the past to remain present, thus reinscribing the aesthetics of brevity on the broader scale, with potential implications for understanding Tarkovsky's entire oeuvre.

As found in Tarkovsky's work, the double exposure is an attempt to instantaneously force two chronotopes (as Mikhail Bakhtin would call them) into one, in the interests of nostalgia and brevity. ${ }^{39}$ The Sacrifice represents just such a concise meeting of two incompatible continua at the level of script and structure, but it is in principle not so different from the concise juxtapositions found in the photographs discussed in this section.

\section{Conclusion}

The aim of this article was to shed new light on Tarkovsky's work, away from the doctrinaire readings inspired by Sculpting in Time. It has also been to discuss his Polaroid work critically, to pick up on and describe some of the details of a lesser-known part of Tarkovsky's art, and to show the thematic coherence between his films and photography.

Tarkovsky was less interested in the long take for its own sake, or for its ability to 'capture time' per se. He was using the long take to look for these small, seemingly insignificant details that could become loaded with significance. The long take was a way to filter out what was superfluous and focus his audience's attention on other matters. But Tarkovsky also found still photographs fascinating, because they allowed a similar experience of the uncanny. As Mulvey notes, 'unlike the photograph, a movie watched in the correct conditions (24 frames a second, darkness) tends to be elusive.' ${ }^{40}$ Photography (and specifically the Polaroid shot) for Tarkovsky was not elusive, it gave him a chance to pin down his visual and thematic obsessions during the making of Nostalghia, and paved the way for some of the key ideas in The Sacrifice, such as the anecdote of the accidental double exposure, the telescoping of time and space in the film's celebrated penultimate shot, and the fact that the whole film is in fact two stories transposed on top of each other. ${ }^{41}$ If Tarkovsky's long take makes us feel the passing of time, then the brevity and immediacy of the Polaroid allow us a sudden contact with the past, a bringing of one tense into another, just as the double exposure that ends Nostalghia brings Italy and Russia, and therefore the protagonist's idyllic past and his stifling present condition, together in a single image (see Fig. 2). As well as being a double exposure, this image encapsulates the charged emotional details of the punctum and the juxtaposition of the Haiku's aesthetics of brevity. Known for his obsession with duration, Tarkovsky's mobilization of the brevity of two images juxtaposed, and of the photograph's embalmed fraction of a 
second show us how we can move beyond the views expressed in Sculpting in Time to a more subtle, supple understanding of Tarkovsky's all too brief oeuvre.

\section{Birkbeck College, University of London}

\section{Notes}

1. For a discussion of Tarkovsky's interest in Haiku, see Tollof Nelson, 'Theoretical Apparitions of Haiku: An Intermedial Interrogation of Modernity', Cinemas: Journal of Film Studies, 10 (2000), 185-203.

2. For information on Olga Surkova's co-authorship of the book, see Olga Surkova, Tarkovsky vs Tarkovsky, trans. by Krill Galetski Nostalghia.com

<http://www.acs.ucalgary.ca/ tstronds/nostalghia.com/TheTopics/Surkova1.html> [accessed July 2010]

3. Andrei Tarkovsky, Sculpting in Time: Reflections on the Cinema, trans. by Kitty HunterBlair (Austin: University of Texas Press, 2006), p. 118.

4. Instant Light, ed. by Giovanni Chiarmonte and Andrei A. Tarkovsky (London: Thames and Hudson, 2004), p. 7.

5. Natasha Synessios, Mirror(New York: Tauris, 2001), pp. 42-47.

6. Synessios, Mirror, pp. 42-47.

7. Chiaramonte, Instant Light, p. 7.

8. Tarkovsky's defection to the West is usually referred to by his admirers as his exile. Though it was doubtless not an easy decision to make, Tarkovsky defected voluntarily and was not exiled. He felt that he had been continually harassed and obstructed by the Soviet authorities, and a dispute over Nostalghia, which was originally intended as an Italian/Soviet co-production, brought matters to a head.

9. Susan Sontag, On Photography (Penguin: London, 2008), p. 19.

10. Andrei Tarkovsky, Time Within Time: The Diaries 1970-1986, trans. by Kitty Hunter-Blair (London: Faber and Faber, 1994), p. 219.

11. Tarkovsky, Time Within Time, p. 15.

12. The word nostalgia comes from the Greek 'from nostos meaning to return, and algia, meaning longing or sickness'. The term was coined by Swiss doctor Johannes Hofer in 1688 as a medical condition afflicting soldiers fighting for long periods abroad. See Svetlana Boym, The Future of Nostalgia (New York: Basic Books, 2001), pp. xiii-xix. Hollis Frampton explains his own understanding of the term: 'In Greek the word means "the wounds of returning". Nostalgia is not an emotion that is entertained; it is sustained. When Ulysses comes home, nostalgia is the lumps he takes, not the tremulous pleasures he takes from being home again.' Quoted in Rachel Moore, Hollis Frampton (nostalgia)(London: Afterall, 2006), p. 1.

13. Sontag, On Photography, pp. 18-19.

14. Jerome Boyd-Maunsell, 'Review of Andrei Tarkovsky, White Space Gallery, London, UK', Frieze Magazine < http://www.frieze.com/issue/review/andrei_tarkovsky> [accessed May 2011]

15. Laura Mulvey, Death $24 x$ a Second: Stillness and the Moving Image (London: Reaktion, 2006), p. 55.

16. Roland Barthes, Camera Lucida, trans. by Richard Howard (London: Vintage, 1990), pp. 43, 51.

17. Mulvey, Death $24 x$ a Second, p. 58.

18. Barthes, Camera Lucida, p. 45.

19. Although Tarkovsky never acknowledged Bazin directly, he owed a huge debt to the milieu of Italian neorealism which Bazin championed, and certain sections of Sculpting in Time do bear a striking resemblance to Bazin's work.

20. Tarkovsky, Sculpting in Time, p. 140.

21. Frampton comments: 'When I came to print the negative, an odd thing struck my eye. Something, standing in the cross-street and invisible to me, was reflected in a factory window, and then reflected once more in the rear-view mirror attached to the truck door. It was only a tiny detail. Since then, I have enlarged this small section of my negative 
enormously; the grain of the film all but obliterates the features of the image. It is obscure, by any possible reckoning, it is hopelessly ambiguous. Nevertheless, what I believe I see recorded, in that speck of film, fills me with such fear, such utter dread and loathing, that I think I shall never dare to make another photograph again.' Moore, Hollis Frampton (nostalgia), p. 88. Frampton's film can be watched in full, courtesy of Ubuweb, at <http://www.ubu.com/film/frampton_nostalgia.html> [accessed September 2011]

22. Bright, Bright Day, ed. by Stephen Gill (London: White Space Gallery, 2008), p. 75.

23. Chiarmonte, Instant Light, p. 51.

24. Tarkovsky, Sculpting in Time, p. 66.

25. Tarkovsky, Sculpting in Time, p. 67.

26. Tarkovsky, Sculpting in Time, p. 66.

27. Makoto Ueda, 'Basho on the art of the Haiku: Impersonality in Poetry', in Japanese Aesthetics and Culture: A Reader, ed. by Nancy G. Hume (New York: State University of New York Press, 1995), pp. 151-76 (p. 166).

28. Roland Barthes, Empire of the Sign, trans. by Richard Howard (New York: Hill and Wang, 1982), p. 83.

29. Barthes, Camera Lucida, p. 49.

30. Late Spring, dir. by Yasujiro Ozu (Shochiku Films, 1949).

31. Kiju Yoshida, Ozu's Anti-Cinema, trans. by Daisuke Miyao and Kyoko Hirano (Ann Arbor: University of Michigan Press, 2003), p. 84.

32. Gill, Bright Bright Day, p. 111.

33. Chiarmonte, Instant Light, p. 109.

34. Evgeny Tsymbal, 'Tarkovsky: Seer or Cinematographer?', Lecture given at Queen Mary College, University of London, Tuesday, 4 March 2008.

35. See for example John Darwell, Legacy: Photographs from the Chernobyl Exclusion Zone (Stockport: Lewis, 2001)

36. Chiarmonte, Instant Light, p. 71.

37. Boym, The Future of Nostalgia, p. xiv. Boym makes no reference to Tarkovsky in the book, though this comment seems to be an uncanny description of Tarkovsky's final two films. Rachel Moore remarks that Boym's description of cinematic nostalgia is 'seemingly pulled from the air’ but notes its relevance for discussing Hollis Frampton’s (nostalgia). See Moore, Hollis Frampton (nostalgia), p. 62.

38. Vida T. Johnson and Graham Petrie, The Films of Andrei Tarkovsky: A Visual Fugue (Indianapolis: Indiana University Press, 1994), p. 172.

39. Bakhtin's concept of the chronotope stresses the immutability of space and time in literary works. He proposed that literary styles hold their own chronotopes, the spatio-temporal matrices that lie under each narrative. The social conditions of each epoch determined the chronotope, so that we can tell something about ancient Roman society and the values it held through the way it represents time and space in works such as The Golden Ass and Satyricon. See Mikhail Bakhtin 'Forms of Time and the Chronotope in the Novel', in The Dialogic Imagination, ed. by Michael Holquist, trans. by Holquist and Caryl Emerson (Austin: University of Texas Press, 1981), pp. 84-254.

40. Mulvey, Death $24 x$ a Second, p. 66.

\section{Works Cited}

Bakhtin, Mikhail, 'Forms of Time and the Chronotope in the Novel', in The Dialogic Imagination, ed. by Michael Holquist, trans. by Holquist and Caryl Emerson (Austin: University of Texas Press, 1981), pp. 84-254

Barthes, Roland, Camera Lucida, trans. by Richard Howard (London: Vintage, 1993)

-- $\quad$ Empire of the Sign, trans. by Richard Howard (New York: Hill and Wang, 1982)

Boyd-Maunsell, Jerome, 'Review of Andrei Tarkovsky, White Space Gallery, London, UK', Frieze Magazine

< http://www.frieze.com/issue/review/andrei_tarkovsky> [accessed May 2011]

Boym, Svetlana, The Future of Nostalgia (New York: Basic Books, 2001) 
Chiarmonte, Giovanni, and Andrei A. Tarkovsky, eds, Instant Light (London: Thames and Hudson, 2006)

Darwell, John, Legacy: Photographs from the Chernobyl Exclusion Zone (Stockport: Lewis, 2001)

Gill, Stephen, ed., Bright, Bright Day (London: White Space Gallery, 2008)

Johnson, Vida T., and Graham Petrie, The Films of Andrei Tarkovsky: A Visual Fugue (Indianapolis: Indiana University Press, 1994)

Moore, Rachel, Hollis Frampton (nostalgia) (London: Afterall Books, 2006)

Mulvey, Laura, Death $24 x$ a Second: Stillness and the Moving Image (London: Reaktion Books, 2006)

Nelson, Tollof, 'Theoretical Apparitions of Haiku: An Intermedial Interrogation of Modernity', Cinemas: Journal of Film Studies, 10 (2000), 185-203

Sontag, Susan, On Photography (London: Penguin, 2008)

Surkova, Olga, Tarkovsky vs Tarkovsky, trans. by Krill Galetski, Nostalghia.com

$<$ http://www.acs.ucalgary.ca/ tstronds/nostalghia.com/TheTopics/Surkova1.html > [accessed July 2010]

Synessios, Natasha, Mirror (New York: Tauris, 2001)

Tarkovsky, Andrei, Sculpting in Time: Reflections on the Cinema, trans. by Kitty Hunter-Blair (Austin: University of Texas Press, 2006)

-- $\quad$ Time Within Time: The Diaries 1970-1986, trans. by Kitty Hunter-Blair (London: Faber and Faber, 1994)

Tsymbal, Evgeny, 'Tarkovsky: Seer or Cinematographer?', Lecture given at Queen Mary College, University of London, Tuesday, 4 March 2008

Ueda, Makoto, 'Basho on the art of the Haiku: Impersonality in Poetry', in Japanese Aesthetics and Culture: A Reader, ed. by Nancy G. Hume (New York: State University of New York Press, 1995), pp. 151-76

Yoshida, Kiju, Ozu's Anti-Cinema, trans. by Daisuke Miyao and Kyoko Hirano (Ann Arbor: University of Michigan Press, 2003) 